\title{
Kuidas Soomes, Ann? Aidi Valliku noorsooraamatute retseptsioonist Soomes
}

\author{
ELE SÜVALEP \\ Oulu Ülikool
}

Ülevaade. Artiklis vaadeldakse Aidi Valliku kahe soome keelde tõlgitud noorteraamatu vastuvõttu Soomes, toetudes trükis ilmunud arvustustele, internetis esitatud kommmentaaridele ja hinnangutele, ning lisaks arvamustele, mida avaldasid eesti lastekirjanduse kursuse kuulajad Oulu ülikoolis 2008. aastal. Sissejuhatavalt on puudutatud noortekirjanduse ja noorsookirjanduse mõisteid ning seejärel lühidalt noorsookirjanduslike tekstide eripära, mis on oluline tõlkimise ja retseptsiooni seisukohalt. Materjali analüüsides ilmnes, et lugejatepoolseid vaidlusi tekitasid eeskätt lugude lõpplahedused, millega liiga ülekaalukaks on tõusnud n-ö vanema inimese vaatepunkt, st noorsookirjandusele iseloomulik kasvatuslik aspekt. Arutlusi sünnitas ka raamatute keelekasutus. Nii tundus raamatu "Kuidas elad, Ann?" peategelase jutustajakõne osale lugejaist liiga kirjakeelne, võrreldes ema värvika päevikustiiliga, ja sellest tulenevalt Ann ise tegelasena kahvatum kui ta ema. Üldine vastuvõtt, eriti esimese raamatu puhul, oli siiski üllatavalt positiivne. Teatud noorsookirjanduslikule "piiratusele" vaatamata pakkusid Anni-raamatud enamikule huvi, andsid ettekujutuse noorteprobleemidest ja -kirjandusest Eestis.

Võtmesõnad: noortekirjandus; tõlkimine; retseptsioon; eesti keel; soome keel 


\section{Noortekirjandusest ja noorsookirjandusest}

2001. aastal ilmunud Aidi Valliku noorteraamat "Kuidas elad, Ann?" jõudis Soome õige kiiresti. Juba aasta hiljem, 2002, andis suurkirjastus Otava selle välja Varja Arola tõlkes pealkirjaga "Ei mikään kiltti tyttö" ("Üldse mitte kena tüdruk"), ühena esimestest raamatutest Otava tõlkelise noortekirjanduse sarjas "Voltti" ("Salto"). Järg "Mis teha, Ann?" (eesti keeles 2002) ilmus pealkirjaga "Pelkkää vedätystä” ("Haneks tõmmatud”, 2004) sama kirjastuse samas sarjas.

Noortekirjandus on teatud mõttes eriline: see on raskesti piiritletav üleminekuala, mida on nimetatud isegi omaette, "laste ja täiskasvanute kirjanduse vahepealseks vormiks" (Lastekirjanduse sõnastik: 134). Tegelikult leidub ühelt poolt selliseid noortekirjanduslikke tekste, mis samal ajal kuuluvad n-ö suurde kirjandusse, kasvõi J. D. Salingeri "Kuristik rukkis" ja Sass Henno "Mina olin siin”, ja teisalt niisuguseid, mis jäävad üsna selgesti just laste- ja noorsookirjanduse rubriiki, eesti traditsiooni kohaselt lastekirjanduse katusmõiste alla (Krusten 1995: 14). Näiteks Silvia Rannamaa Kadri-diloogia, Jaan Rannapi koolilood ja ka Aidi Valliku Anni-raamatud.

Lastekirjanduslikke noorteraamatuid on üldiselt nimetatud n o o r s o o-raamatuteks, ja ehkki uuemal ajal eelistatakse Eestiski just n o o rte kirjanduse mõistet (Lastekirjanduse sõnastik: 34), kasutan oma käsitluses ajaloolist noorsookirjanduse terminit, eriti siis kui tuleb eristada lastekirjanduslikku noortekirjandust muust. Noorsookirjandust iseloomustab lastekirjandusele omane autori ja lugeja suhe, sellesse kirjandusvalda otsekui sissekodeeritud vastuolu, mis mõjutab ka vastavate tekstide vastuvõttu. Lastekirjandust defineeritakse adressaadi või lugeja (laps) ja autori (täiskasvanu) kaudu (Krusten 1995: 13; Lastekirjanduse sõnastik: 101). Lapsele ja noorele eeldatavalt sobiva teksti loob täiskasvanu, kelle õpetav-kasvatav "hääl" on alati raamatus kuuldav, kas rohkem või vähem. Kui väiksemate laste jaoks on kirjutaja vanemlik olek suhteliselt loomulik, siis teismeline lugeja protestib täiskasvanu autoriteedi vastu. Nii tekitavadki 
noorsooraamatud lugejais sageli kriitikat ja vastuväiteid. (Vt Süvalep 2006.)

Noorsooraamatuid tõlgitakse teistesse keeltesse üldiselt vähem kui täiskasvanute kirjandust, ja ka vähem kui väiksematele lastele mõeldut. Eespool viidatud autori-lugeja probleem on selle üks, ehkki mitte ainus põhjus. Eesti noorsookirjanduse varasemate soomenduste ja Soomes leviku kohta puuduvad mul andmed, ja nii on põhjust just Valliku raamatutest lähtuvalt arutleda, kuidas nüüdisaegne eesti noorsooraamat Soome lugejaile meeldis ja kuivõrd hästi nende meelest õnnestus Vallikul läbi tulla kitsaskohtadest, mis reeglina noorsookirjandust pigistavad.

Eestis läks edukalt. "Kuidas elad, Ann?” võitis 2000. aastal peaauhinna Eesti Lastekirjanduse Teabekeskuse ja kirjastuse Tänapäev noorsoojutuvõistlusel. Raamatu põhjal on tehtud raadiokuuldemäng (2006) ja teatrilavastus (Rakvere Teater 2006). Arvustused olid suurelt jaolt positiivsed, kuid loomulikult omajagu ka vaieldi (Krusten 2002). Nüüdseks kuulub "Kuidas elad, Ann?” Eestis koolilektüüri nimistutesse, seda laenutatakse palju raamatukogudest, ilmunud on kaks kordustrükki $(2003,2008)$. Esimese raamatu tuules on saanud populaarseks ka järgnevad Anni-tekstid, kõigepealt “Mis teha, Ann?”. 2007. aastal valmis režissöör Rainer Sarneti käe all Aidi Valliku ja Peeter Sauteri stsenaariumi järgi film "Kuhu põgenevad hinged?" ning samal aastal ilmus ka Aidi Valliku vastav raamatuversioon "Mis sinuga juhtus, Ann?"

Ka Soomes oli ilmumisjärgne vastukaja Valliku raamatutele, eriti esimesele, küllalt elav. Iseäranis palju arvamusi ja kommentaare tuli noortelt lugejatelt interneti kaudu; neid on seal veel praegugi. Leidub ka trükitud arvustusi-kommentaare perioodikas. Üsna ilmselt pole mu käsutuses olnud kõiki võimalikke allikaid, kuid olulisemad arvamused ja hinnangud peaksid ka antud valikust selguma. Lisaks toetun 2008. aasta kevadsemestril Oulu ülikoolis peetud lastekirjanduse kursusest osavõtnute seisukohtadele. 


\section{Erinevad lugejad, erinevad arvamused}

"Ei mikään kiltti tyttö" reklaamib kaane siseküljel teose edu Eestis: Aidi Vallikin palkittu romaani on ollut suurmenestys kotimaassaan Virossa (Vallik 2002a). Autoriteetsemad arvamused pärinevad Helsingin Sanomates kirjutanud Suvi Aholalt, Aamulehti Kanerva Eskolalt, ka soome emakeeleõpetajate lehes Virke arvustanud Jani-Petteri Antamolt.

Ahola kirjanduskommentaar "Vakavuus on tarpeen" (Ahola 2002) puudutab tõsidust noortekirjanduses ja tõsiste probleemide nappust, võrreldes üldiselt vohava ajaviitelisusega. Tõsise noortekirjanduse positiivsete näidetena toob Ahola kolm Otava "Voltti"-sarja tõlkeraamatut. Kaks neist kuuluvad ameerika tuntud tegijatele Joyce Carol Oatesile ("Big Mouth \& Ugly Girl”, soome keeles pealkirjaga "Syntipukki”) ja David Klassile ("You Don't Know Me" = "Ette minua tunne"). Kolmandana on väärikasse seltskonda arvatud noor ning maailmas tundmatu eesti kooliõpetaja Aidi Vallik oma esimese noorsooromaaniga "Kuidas elad, Ann?" = "Ei mikään kiltti tyttö".

Ahola peab temaatiliselt kõige silmahakkavamaks Oatesi raamatut terrorismist ja pommiohust koolis, kuid ta tunnustab täielikult ka Valliku jutustuslaadi värskust traditsioonilisema aine käsitlemisel. Eraldi tõstab arvustaja esile noore kirjaniku antud meeldejäävat ja sotsiaalselt tundlikku sissevaadet Eesti ellu ja eesti noorte mõtteilma. Noorteraamatute suure ja küllaltki ajaviitelise massi taustal pakuvad Oatesi, Klassi ja Valliku raamatud Ahola meelest tõelist lugemiselamust.

Ka Jani-Petteri Antamo käsitleb ajakirjas Virke kolme "Voltti"-sarja raamatut (Antamo 2002). Tema kõrgeima hinnangu saab Klass, ent ka Vallik pälvib kiidusõnu ja koolihinde 9. "Ei mikään kiltti tyttö" on Antamo arvates hästi loetav, ükski osa ei ole igav või tüütu. Tegelasi on palju, kuid mitte üleliia, ning nendega on kerge samastuda. Ka kohad, kogu miljöö on kujutatud hästi, maastikud on otsekui silmaga nähtavad. Erinevalt mõnest teisest hindajast rõhutab Antamo just loo tugevat lõppu, mis on tema meelest tõeliselt hea ja ettearvamatu (Antamo 2002: 65). 
Eskola kirjutis (Eskola 2002) sisaldab peamiselt Valliku isiku ja raamatu tutvustust. Lähtutakse paljuski Vallikuga tehtud intervjuu seisukohtadest. Ent Eskola arvustuse pealkiri on üsna kitsalt raamistav "Pitää kirjoittaa huumeistakin", ja torkabki silma, et järgnevates soome koolide kirjandusnimestikes figureerib raamat mõnelgi korral teemarubriigis "Huumeet" (nt Kirja koulussa 2008). Kirjanduslikku analüüsi on Eskola kirjutises napilt, kuid selgelt tunnustatakse valitud teema elulisust ja noortepärasust, taoliste raamatute vajalikkust.

Pikem arvustus on veel ajakirjas Lukufiilis, mis on noorte tegijate ja kirjutajate leht. Oulu Nuku Sõnakunstikooli õpilane Anna Salmi (Salmi 2002) on rangem kui vanemad kirjutajad. Ta annab raamatule hindeks $3 / 5$ ja väidab üsna enesekindlalt, et raamatu temaatika on aktuaalne ja põnev, kuid kipub jääma mõnevõrra jäiga jutustamise varju. Kirjakeel ei sobivat "raju" teemaga ega tõlgendavat usutavalt noorte mõtteid. Sündmustik ei paku eriti üllatusi. Positiivsena tõstab noor arvustaja esile siinkohal võrdlemisi sarnaselt Eestis ilmunud arvustustega - Anni ema päevikuid, mistõttu loo peategelaseks tõusebki tema silmis ema. Kokkuvõttes nenditakse, et raamat jätkab noorteromaanide stiilitraditsiooni. Tegelaskond kipub jääma pinnapealseks, seski suhtes võinuks teos olla varjundirikkam.

Internetist leidsin päris suure hulga õpilaste ja noorte kokkuvõtlikke hinnanguid raamatule, ka ümberjutustusi ja sisututvustusi. Muuhulgas ilmneb, et raamatukogudest on korduvalt küsitud andmeid autori kohta ja raamatut ei ole võimalik alati saada. Noorte hinnangud on valdavalt positiivsed, teinekord lausa ülimalt. Näiteks nimemärgi star küsimusele 4.1.2008: Maailman paras kirja, jonka ootte lukenu? on -ReDu 5.1.2008 vastanud: Ei mikään kiltti tyttö - Aidi Vallik. MAAILMAN PARAS KIRJA. Ja tätä ei voita mikään (MissMix keskustelut 2008).

Teise Anni-raamatu "Pelkkää vedätystä" vastuvõttu Soomes võiks pidada mõõdukalt heaks, nagu: Ei ihan edellisen Vallikin kirjan (Ei mikään kiltti tyttö) tasoinen, mutta "mukaansa tempaava" ja todenoloinen hyvä kertomus nuoresta tytöstä. Kannattaa lukea (Pelkkää vedätystä 2006). Arvustusi on vähem ja üksikhinnangud lahknevad rohkem. Eri meelt on 
oldud Anni kasuisa lastekodumineviku kujutamise suhtes. Turun Sanomate arvustaja pidas valitud jutustusviisi ja isa lapsepõlve kujutamist kõrvuti nüüdisnoorte, eriti Gregori omaga, õnnestunuks (Heinilä 2004), ent mõnele lugejale tundus isaga seotud liini esitus liiga naturalistlik, lausa Dickensi-vaimuline (Forsblom 2005). Põhimõttelist vastuseisu äratas Anni isa karmus Gregori suhtes (Rauhala 2005; Kyrö 2008), kui Gregor ei osutunud nii mehiseks kui isa. Eriti häirisid isa hukkamõistvad sõnad Gregorile: Olen sinusuguseid lollpäid näinud rohkem kui vaja. Paraku kasvasin ise selliste seas üles. Mis teha, lapsepõlve ei saa valida. Aga edaspidist elu küll. Ja sina, sitaratas, oled minu arvates valesti valinud. Oma asi. Aga sellele majale ära enam lähedale tule. (Vallik 2002b: 133) Niisugust hoiakut ei arvatud leiduvat soome noortekirjanduses (Rauhala 2005).

Kõrvalpõikena: hoopis üksmeelsema vastuvõtu leidis "Mis teha, Ann?” Eesti lõunanaabrite juures Lätis (Vallika 2006), saades seal aasta parima tõlkelise noorteraamatu auhinna, nagu ka selle tõlkija Maima Grīnberga. Ju siis olid kujutatud karmid olud ja hoiakud lätlastele lähedasemad. Läti keeles on ilmunud ka Anni-lugude esimene osa (Vallika 2001), mis samuti on olnud väga loetav ja populaarne.

Pea kõik kirjutajad Soomes tunnistasid, et mõlema Valliku raamatu kaudu saadud pilt või ettekujutus eesti noortest ja Eesti elust on pakkunud suurt huvi. Raamatud on mitmekesistanud lektüüri, mille tõlkelises osas on muidu domineerinud rootsi oma, teistsugune oma tolerantsis ja "pehmetes" väärtustes (Rauhala 2005). Soome enda noortekirjandus on eluvaate ja väärtuste seisukohalt ehk kuskil Rootsi ja Eesti vahel.

\section{3. Üldist ja olulisemat Anni Soome-retseptsioonis}

Kas soome lugejate ja kriitikute arvamused ütlevad ka midagi üldisemat noorsookirjanduse autori-lugeja suhte kohta, nagu see väljendub Annilugudes? Mingil määral küll, kui vaadelda mõningaid kriitilisi või lahknevaid hinnanguid.

Alustada võiks teisest raamatust "Pelkkää vedätystä", kus lugejaile osutus proovikiviks lastekoduvägivalla karm kujutus, ja veel olulisem - 
tolle ränga olelusvõitluse taustalt võrsunud hävitav hinnang eksinud noorukile. Anni isa sõnu tajuti selgesti kui autoripositsiooni, teose juhtmõtte väljendust. Arvustajad sidusid sellegi - vähemalt osaliselt - Eesti oludega ja vastavate väärtushinnangutega. Võimalik siiski, et omajagu provotseeris vastuväiteid ka noorsookirjanduse olemuslikule konfliktile viitav põlvkondlik vastasseis Anni isa ja Gregori vahel, mis lahendatakse üsna ühemõtteliselt isa kasuks, täiskasvanu õigus jääb peale. See, et Gregor on halb, tuleb esile loo kõigi vaatepunktide ja isikute kaudu, kuigi on valitud hea ja mitmekülgne jutustamisviis, mis peaks võimaldama vältida nii ühest hinnangut. Läbi mitme fookuse antud ja suures osas kolmandas isikus esitatud jutustust pidasid lugejadki üldiselt heaks, ent leidub ka arvamus: Kirjassa on niin monta kerrosta, että lukija turhautuu helposti (Forsblom 2005).

Esimese Anni-loo “Ei mikään kiltti tyttö” vastuvõtu analüüs on omajagu keerulisem. Pidas ju suurem osa hindajaid - vanemad arvustajad ja noored "lihtlugejad" internetis - raamatut oluliste vastuväideteta heaks ja õnnestunuks. Nõudlikum noorlugeja Anna Salmi polnud aga päris rahul sündmustiku, keelekasutuse, ennekõike peajutustaja Anni tekstiga; kriitikat tuli ka Oulu üliõpilastelt. Viimased arutlesid eriti loo lõpu üle, pidades seda ebausutavaks ja ema idealiseerivaks. Ka Anni tekst mõjus osale lugejaist liiga kirjakeelsena, kandis täiskasvanuliku mõtteviisi märke, kuigi tekstis oli ka veenvamaid osi. Kõigile meeldis ema noorpõlvepäevik, mida tajuti ehtsamana ja moraalivabamana. Tegelikult on ka ema päevikus, eriti lõpupoole selgelt ideoloogilisi osi, kui ema otsustab oma elu muuta. Päeviku omapärane kirjaviis, mis seostub punkarite põlvkonnaga ja eesti punkluulega, on aga mõjuv ja terviklik. Otsustades lugejahinnangute järgi, oli ka soomendus õnnestunud. Siinkohal lühike tekstivõrdlus.

Läxime koertenäitusele lällama. Sealt aeti meid varsti minema, sest me lasime käpuli \& hakkasime koerte peale haukuma \& vaesed loomad sattusid sellest nii ähmi täis, et neid oli täitsa võimatu exponeerida. Lõpux oli terve see näituseplats yxainus suur hullumaja, korraldajad 
sebisid \& yritasid meist lahti saada \& penid kiunusid \& ulgusid \& haukusid, aga kartsid. Või olid lihtsalt veidi šokeeritud. (Vallik 2001: 21)

Mentiin koiranäyttelyyn mellastaan. Sieltä meidät heitettiin äkkiä pihalle, koska me mentiin kontalleen \& alettiin haukkua koirille \& eläinparat hermostu siitä niin ettei niitä voinu enää pitää näytillä. Lopulta se koko näyttelypaikka oli yx iso hullujenhuone, järjestäjät hääri \& yritti päästä meistä eroon \& piskit vinku \& ulis \& haukku peloissaan. Tai oli yksinkertaisen pikku sokissa. (Vallik 2004: 24)

Niisugune loosisene minajutustus sobib noorsookirjandusse väga hästi. Seevastu minajutustuse kasutamine põhitekstina, nagu on Annipoolne kogu sündmustiku jutustamine, on mõneti riskantsem, selle kaudu mitmehäälsuse loomine keerukam ja eri suhtumiste väljendamine "implitsiitsem" kui kolmandas või vahelduvas isikus jutustamisel (McCallum 1999: 31). Noore, väga piiratud teadmistega jutustaja kõne kaudu tuleb autoril edasi anda kõike vajalikku, niihästi erinevaid seisukohti kui positiivset programmi. Noor lugeja ootab aga selleltki tekstilt noortepärasust, kõnelist ja mõttelist usutavust, ja protestib, kui autori täiskasvanuhoiak teismelise pähe istutatakse ... Viitan veelkord Anna Salmi arvustusele: Olisi ollut kiinnostavaa peilata tarinaa myös muiden kirjan henkilöiden ajatusten ja tulkintojen kautta (Salmi 2002: 9).

Tavaliselt antakse jutustajakõnet edasi neutraalsemalt ja õigekeelsemalt ka siis, kui jutustajaks on noor peategelane. Noorteslängi saab kasutada põhiteksti sees tegelaskõnes. Vallik on Anni-poolse jutustuse vormistanud kirjakeeles, milles küll leidub suulisele kõnele iseloomulikku väljendust ja kerget slängi. Tõlkija Varja Arola on üldiselt järginud Valliku stiilipõhimõtteid, kuigi alati pole leidunud vasteid eesti kõnekeele ühele või teisele nüansile. Tõenäoline, et soome lugejad tajuvadki kõne- ja kirjakeelt teineteisest rohkem erinevana. Eestikeelne variant on igatahes üsna stiilne ja terviklik. Piirdun siingi lühinäidetega originaalist ja tõlkest.

Üldiselt ei olnud tuju isegi teistega suhelda. Rääkisin küll juttu, vastasin ja naeratasin, aga millest jutt käis, ei tabanud. Ei jäänud meeldegi. Nagu 
automaat. Õpsid imestasid mu loiduse üle ja nende pärimine tüütas mind. No mis see nende asi on. Midagi pole juhtunud. Välja arvatud see, et ma kaotasin oma ema. Mõtteliselt. (Vallik 2001: 19)

Ei huvittanut olla kenenkään kanssa tekemisissä. Juttelin kyllä, vastasin ja hymyilin, mutta en tajunnut, mistä puhuttiin. Mitään ei jäänyt mieleen. Olin kuin automaatti. Opet ihmettelivät innottomuuttani, ja heidän utelunsa kyllästytti minua. Mitäpä se heille kuuluu. Mitään ei ole tapahtunut. Paitsi että menetin äidin. Henkisesti. (Vallik 2002a: 23)

\section{Lõpetuseks}

Kõigele vaatamata jäi raamatute retseptsioonist Soomes hea ja elav mulje. Ka enamik Oulu üliõpilasi andis Anni-lugudele hea hinnangu. Kursusel osalenud Anna Kyrö on arutlenud nii:

"Viralliseksi määritelmäksi muodostuneen luonnehdinnan mukaan hyvä lastenkirjallisuus on ylipäätään hyvää kirjallisuutta. Toisen luonnehdinnan mukaan hyvä lastenkirjallisuus tekee aikuisista hetkeksi lapsia tai nuoria: saa heidät eläytymään näiden asemaan. Virolaisen Aidi Vallikin kaksi suomennettua nuorisoromaania täyttävät molemmat ehdot. Sen lisäksi ne täyttävät myös nuorisokirjallisuuden kolmannen ehdon: tarjoavat nuorille lukijoille ratkaisuja teosten käsittelemiin ongelmiin." (Kyrö 2008)

Nüüdisaegne noortekultuur on nii kirev ja võimalusterohke, et noorsookirjandusel pole kaugeltki endist osatähtsust. Noorteraamatuidki on maailmas sedavõrd palju, et isegi oma kitsal keelealal populaarsuse saavutamine pole kerge, rääkimata laiemast levikust. Teeb rõõmu, et Aidi Valliku Ann on värskendanud eesti noorsookirjanduse palet ning saanud tuntuks meie lähinaabrite juures. 


\section{Kirjandus}

Ahola, Suvi 2002. Kommentti: vakavuus on tarpeen. - Helsingin Sanomat 18.10. Antamo, Jani-Petteri 2002. Otavan uusi Voltti-sarja. - Virke 4, 64-65.

Eskola, Kanerva 2002. Pitää kirjoittaa huumeistakin. - Aamulehti 16.10., 7.

Forsblom, S. 2005. Pelkkää vedätystä. - www.tfg.tartu.ee/virtuaalkass (17.03.2010).

Kirja koulussa 2004. Kirja koulussa-kampanjan kirjalista. - www.kirjakoulussa.fi (17.03.2010).

Heinilä, A. 2004. Elämä on parasta huumetta. - Turun Sanomat 18.12.

Krusten, Reet 1995. Eesti lastekirjandus. Tartu: Elmatar.

Krusten, Reet 2002. Õige valik, Ann. - Postimees 4.05., 9.

Kyrö, Anna 2008. Kuinka nuoruudesta selviää ihmisenä? - www.kemi.fi/rinki/vallik.html (17.03.2010).

Lastekirjanduse sõnastik 2006. Tallinn: Eesti Lastekirjanduse Teabekeskus.

McCallum, Robyn 1999. Ideologies of Identity in Adolescent Fiction. The Dialogic Construction of Subjectivity. New York, London: Garland Publishing.

Miss Mix Keskustelut 2008. - www.missmix.fi/keskustelut/kirjat (17.03.2010).

Pelkkää vedätystä 2006. - www.kirjainfo.com/kirja/9511193791 (17.03.2010).

Rauhala, J. 2005. Aidi Vallik: Pelkkää vedätystä. - Naakan lehti. www.peda.net/ verkkolehti (17.03.2010).

Salmi, Anna 2003. Äidin ja tyttären harharetket. - Lukufiilis 2, 9.

Süvalep, Ele 2006. Kes kirjutab? Kes loeb? Noorteraamatu autori ja lugeja vahekorrast. - Raamatukogu 4, 64-65.

Vallik, Aidi 2001. Kuidas elad, Ann? Tallinn: Tänapäev.

Vallika, Aidi 2001. Ka tev kajas, Anna? Riga: Zwaigzene.

Vallik, Aidi 2002a. Ei mikään kiltti tyttö. Helsinki: Otava.

Vallik, Aidi 2002b. Mis teha, Ann? Tallinn: Tänapäev.

Vallik, Aidi 2004. Pelkkää vedätystä. Helsinki: Otava.

Vallika, Aidi 2006. Ko darit, Anna? Riga: Zwaigne.

\section{Ele Süvalep}

Veeriku 8-3

50407 Tartu, Estonia

ele.suvalep@ut.ee 


\title{
How are you getting on in Finland, Ann? The reception of Aidi Vallik's youth books in Finland
}

\author{
ELE SÜVALEP \\ University of Oulu
}

The Finnish reception of the translations of two youth books by Aidi Vallik is analysed on the basis of published reviews, web comments and judgements, and the opinions expressed by a class on Estonian children's literature held at the University of Oulu in 2008. The introductory part touches upon the concepts of young adult literature and youth literature and, briefly, upon some specific traits of youth literature which are important from the perspective of translation and reception. The analysis of the material revealed that the readers would mainly argue against the final resolutions of the stories as those seem to lay too much emphasis on the adult viewpoint and the didactic aspect. The language use was also found problematic. Notably, in "How are you, Ann?" the main character's narrative seemed too literary, for some readers, especially in comparison with the colourful diary of Ann's mother, which makes Ann less interesting than her mother. The general attitude, especially for the first book, was nevertheless positive enough. Despite the reservations typical of youth literature the books of Ann were found interesting by most readers, providing an idea of Estonian youth problems and youth literature.

Keywords: youth literature; translation; reception; Estonian; Finnish 